\title{
Correlation between obesity and clinicopathological characteristics in patients with papillary thyroid cancer: a study of 1579 cases: A retrospective study
}

\author{
Huijuan Wang ${ }^{1}$, Pingping Wang ${ }^{2}$, Yu Wu ${ }^{3}$, Xiukun Hou ${ }^{1}$, Zechun Peng ${ }^{4}$, Weiwei Yang ${ }^{5}$, Lizhao Guan ${ }^{6}$, Linfei Hu ${ }^{1}$ \\ , Jingtai Zhi ${ }^{1}$, Ming Gao ${ }^{1}$, Xiangqian Zheng ${ }^{\text {Corresp. } 1}$ \\ 1 Department of Thyroid and Neck Tumor, Tianjin Medical University Cancer Institute and Hospital, National Clinical Research Center for Cancer, Key \\ Laboratory of Cancer Prevention and Therapy, Tianjin, Tianjin's Clinical Research Center for Cancer, Tianjin, China \\ 2 Department of Thyroid and Breast Surgery, Rizhao Central Hospital, Shandong, China \\ 3 Department of Head and Neck Surgery, Fujian Cancer Hospital, Fujian Medical University Cancer Hospital, Fujian, China \\ 4 Department of Urology Surgery, Areall, The Second Affiliated Hospital of Hainan Medical University, Hainan, China \\ 5 Department of Otolaryngology-Head and Neck Surgery, Tianjin First Center Hospital, Tianjin, China \\ 6 Department of Biochemistry and Molecular Biology, School of Basic Medical Sciences, Tianjin Medical University, Tianjin, China \\ Corresponding Author: Xiangqian Zheng \\ Email address: xzheng05@tmu.edu.cn
}

Objective: To explore the relationship between body mass index (BMI) and clinicopathological characteristics in patients with papillary thyroid carcinoma (PTC).

Methods: The clinical data of 1579 patients with PTC, admitted to our hospital from May 2016 to March 2017, were retrospectively analyzed. According to the different BMI of patients, it can be divided into underweight recombination(BMI $<18.5 \mathrm{~kg} / \mathrm{m}$ ), normal body recombination $(24.0 \geq \mathrm{BMI}<28.0 \mathrm{~kg} / \mathrm{m} 2)$, overweight recombination $(24.0 \geq \mathrm{BMI}<28.0 \mathrm{~kg} / \mathrm{m} 2)$ and obesity group(BMI $\geq 28.0 \mathrm{~kg} / \mathrm{m} 2)$. The clinicopathological characteristics of PTC in patients with different BMIs group were compared.

Results: In our study, the risk for extrathyroidal extension (ETE), advanced T stage (T III/IV), and advanced tumor-node-metastasis stage (TNM III/IV) in the overweight group were higher, with OR(odds ratio $)=1.99(1.41-2.81), \mathrm{OR}=2.01(1.43-2.84), \mathrm{OR}=2.94(1.42-6.07)$, respectively, relative to the normal weight group. The risk for ETE and T III/IV stage in the obese group were higher, with $\mathrm{OR}=1.82(1.23-2.71)$ and $O R=1.82(1.23-2.70)$, respectively, relative to the normal weight group.

Conclusion: BMI is associated with the invasiveness of PTC. There is a higher risk for ETE and TNM III/IV stage among patients with PTC in the overweight group and for ETE among patients with PTC in the obese group. 


\section{Correlation between obesity and clinicopathological characteristics}

\section{3 in patients with papillary thyroid cancer: a study of 1579 cases:A}

\section{4 retrospective study}

5

Huijuan Wang,MD ${ }^{1}$, Pingping Wang, $\mathrm{MD}^{2}, \mathrm{Yu}$ Wu,MD ${ }^{3}$, Xiukun Hou,MD ${ }^{1}$, Zechun Peng,MD ${ }^{4}$, Weiwei Yang, MD ${ }^{5}$, Lizhao Gan, $\mathrm{PhD}^{5}$, Linfei $\mathrm{Hu}, \mathrm{MD}^{1}$, Jingtai Zhi, $\mathrm{MD}^{1}$, Ming Gao,MD,PhD ${ }^{1}$, and Xiangqian Zheng, MD,PhD ${ }^{1}$

${ }^{1}$ Department of Thyroid and Neck Tumor, Tianjin Medical University Cancer Institute and Hospital, National Clinical Research Center for Cancer, Key Laboratory of Cancer Prevention and Therapy, Tianjin, Tianjin's Clinical Research Center for Cancer, Tianjin 300060, People's Republic of China.

${ }^{2}$ Department of Thyroid and Breast Surgery, Rizhao Central Hospital, Shandong, 276806, People's Republic of China.

${ }^{3}$ Department of Head and Neck Surgery, Fujian Cancer Hospital, Fujian Medical University Cancer Hospital, Fujian, 350001, People's Republic of China.

${ }^{4}$ Department of Urology Surgery, Area II , The Second Affiliated Hospital of Hainan Medical University ,No 48 Baishuitang Road ,Longhua District Haikou City, Hainan, 570311, People's Republic of China..

${ }^{5}$ Department of Otolaryngology-Head and Neck Surgery, Tianjin First Center Hospital, Nankai District of Tianjin Rehabilitation Road No.24,300192, Tianjin, People's Republic of China.

${ }^{6}$ Department of Biochemistry and Molecular Biology, School of Basic Medical Sciences, Tianjin Medical University, Tianjin, 300070, People's Republic of China.

Corresponding Author:

Xiangqian Zheng, MD, PhD

Department of Thyroid Tumor, Tianjin Medical University Cancer Institute and Hospital, West Huanhu Rd, Tianjin, China

Email address: xiangqian_zheng@163.com

\section{Abstract}


29 Objective: To explore the relationship between body mass index (BMI) and clinicopathological

30 characteristics in patients with papillary thyroid carcinoma (PTC).

31 Methods: The clinical data of 1579 patients with PTC, admitted to our hospital from May 2016

32 to March 2017, were retrospectively analyzed. According to the different BMI of patients, it can

33 be divided into underweight recombination $(\mathrm{BMI}<18.5 \mathrm{~kg} / \mathrm{m})$, normal body recombination $(24.0 \geq$

34 BMI $\left.<28.0 \mathrm{~kg} / \mathrm{m}^{2}\right)$, overweight recombination $\left(24.0 \geq \mathrm{BMI}<28.0 \mathrm{~kg} / \mathrm{m}^{2}\right)$ and obesity group(BMI

$35 \geq 28.0 \mathrm{~kg} / \mathrm{m}^{2}$ ). The clinicopathological characteristics of PTC in patients with different BMIs

36 group were compared.

37 Results: In our study, the risk for extrathyroidal extension (ETE), advanced T stage (T III/IV),

38 and advanced tumor-node-metastasis stage (TNM III/IV) in the overweight group were higher,

39 with $\mathrm{OR}$ (odds ratio) $=1.99(1.41-2.81), \mathrm{OR}=2.01(1.43-2.84), \mathrm{OR}=2.94(1.42-6.07)$, respectively,

40 relative to the normal weight group. The risk for ETE and T III/IV stage in the obese group were

41 higher, with $\mathrm{OR}=1.82(1.23-2.71)$ and $\mathrm{OR}=1.82(1.23-2.70)$, respectively, relative to the normal

42 weight group.

43 Conclusion: BMI is associated with the invasiveness of PTC. There is a higher risk for ETE and

44 TNM III/IV stage among patients with PTC in the overweight group and for ETE among patients

45 with PTC in the obese group.

46 Keywords Body mass index; Papillary thyroid cancer; Correlation

47 Introduction

48 The incidence of thyroid cancer has been increasing in recent years worldwide. Thyroid cancer

49 in women has become the fifth most common malignant tumor in the United States [1].Thyroid

50 cancer has become the most common tumor in women in South Korea [2].Thyroid screening and

51 over-diagnosis do not explain the significant increase in the incidence of primary tumors $\geq 4 \mathrm{~cm}$

52 and the incidence of distant metastasis. Although the rate of thyroid cancer detection has 
53 improved, the survival rate has not increased. This indicates that it is necessary to further explore

54 the causes of the increase in the incidence of thyroid cancer which cannot simply be explained by

55 the increase in detection rates. It is also necessary to study this problem from the perspective of

56 factors such as environmental factors and molecular mechanisms $[3,4]$.The real cause of the

57 increase in the incidence of thyroid cancer has not yet been determined; however, environmental

58 factors or lifestyle may contribute to this increase. Several epidemiological studies have

59 confirmed that obesity is positively correlated with the increased risk of thyroid cancer [5-

60 8].However, the correlation between obesity and the invasive clinicopathological features of

61 thyroid cancer remains controversial.[9-12] In this study, the Chinese body mass index (BMI)

62 classification criteria were used to explore whether the clinicopathological characteristics of PTC

63 are different among patients with different BMIs.

\section{Materials \& Methods}

65 Patients

66 A total of 1702 patients with PTC (including thyroid micropapillary carcinoma, PTMC) who

67 received surgical treatment in Tianjin Medical University Cancer Institute and Hospital from

68 May 2016 to March 2017 were considered. After excluding patients with histories of thyroid

69 surgery, antithyroid drug consumption, and thyroxine administration before surgery, 1579

70 subjects were eligible for analysis in this study. Each participant signed an informed consent

71 form, which was uploaded in supplementary materials. This study was approved by the Ethics

72 Committee of the Tianjin Medical University Cancer Institute and Hospital. Ethics Committee

73 reference number is Ek2018117.

74 Methods

75 We performed a retrospective analysis of the patient's gender, age, serum thyroid stimulating

76 hormone (TSH) levels, combined with postoperative pathological features, including tumor size 
77 (maximum diameter of the tumor), lymph node metastasis, multifocality, and the extrathyroidal

78

79

80

81

82

83

84

85

86

87

88

89

90

91

92

93

94

95

96

97

extension (ETE) and TNM stage based on the eighth edition of the Union for International

Cancer Control (UICC)/American Joint Committee on Cancer (AJCC). We reviewed the height and the weight of the patient during admission, calculated BMI according to the Chinese obesity classification standard (BMI $<18.5 \mathrm{~kg} / \mathrm{m}^{2}$, underweight; $18.5 \leq \mathrm{BMI}<24.0 \mathrm{~kg} / \mathrm{m}^{2}$, normal weight; $24.0 \geq \mathrm{BMI}<28.0 \mathrm{~kg} / \mathrm{m}^{2}$, overweight; and BMI $\geq 28.0 \mathrm{~kg} / \mathrm{m}^{2}$, obese)[13].Subsequently, the pathological characteristics including multifocality, tumor size, ETE, lymph node metastasis, T stage, TNM stage of each group were compared.

\section{Statistical analysis}

Logistic regression analysis was used to analyze the relationship between BMI and the clinical pathological features of thyroid cancer. The odds ratio (OR) and 95\% confidence interval were used. The adverse clinicopathological features analyzed included multifocality (number of lesions $\geq 2$ ), tumor size $\geq 1 \mathrm{~cm}$, ETE, lymph node metastasis, high T stage (stage III + IV), and high TNM stage (stage III + IV). Logistic regression (adjusting for age, gender and TSH) was used to analyze the relationship between BMI and the adverse clinicopathological features of PTC. Similarly, logistic regression analysis (adjusting for age and TSH) was used to analyze the relationship between BMI and adverse clinicopathological features of PTC in men and women. For those older than $\geq 55$ years and $<55$ years, logistic regression analysis (adjusting for gender and TSH) of the relationship between BMI and adverse clinicopathological features of PTC was performed.

7 The Chi-square test was used to analyze whether there were differences in gender, age, level of TSH, number of tumors, tumor size, ETE, lymph node metastasis, T stage, and TNM stage among different BMI groups.

Peer) reviewing PDF | (2020:03:46744:1:2:NEW 10 Jun 2020) 
100 Statistical analysis was performed using SAS V9.3 software (Cary, North Carolina, USA) with a

101 statistical significance noted at $\mathrm{P}<0.05$.

102 Results

103 Basic clinical biological characteristics of 346 males and 1233 females were recorded. The age

104 ranged from 18 to 76 years, with an average age of (45.98 \pm 10.93$)$ years, a median age of 46

105 years, 1129 patients $(71.5 \%)$ aged $<55$ years, and $450(28.5 \%)$ aged $\geq 55$ years. BMI ranged from

10616.00 to $48.33 \mathrm{~kg} / \mathrm{m}^{2}$ with mean BMI $25.52 \pm 3.79 \mathrm{~kg} / \mathrm{m}^{2}$. A total of 704 patients $(44.6 \%)$ had

107 lymphatic metastasis,228 (14.4\%) had ETE and 565 (35.5\%) had multifocal tumors. With

108 regards to the T stage, $1322(83.7 \%)$ patients were in the T1 stage and 257 patients $(16.3 \%)$ were

109 in the T3/4 stage. With regards to the TNM stage, 1515 (95.9\%) patients were in stage I and II,

110 and 64 patients $(4.1 \%)$ were in stage III and IV (Table 1).

111 There are differences in the distribution of $\operatorname{gender}(\chi 2=80.28, \mathrm{P}<0.0001)$ and age $(\chi 2=27.05, \mathrm{P}$

$112<0.0001)$ between different BMI groups. BMI is associated with invasion of the envelope

$113(\chi 2=22.25, \mathrm{P}<0.0001)$, T stage $(\chi 2=22.81, \mathrm{P}<0.0001)$, and TNM stage $(\mathrm{P}=0.0002)$ in the

114 pathological features of the tumor(Table 2).

115 We further explored the risk of more aggressive clinicopathological features according to BMI

116 (Table 3). Multiple logistic regression results display that patients who were overweight had a

117 significantly greater risk of ETE $(\mathrm{OR}=1.99[1.41-2.81], \mathrm{P}<0.0001)$, high $\mathrm{T}$ stage $(\mathrm{OR}=2.01[1.43$ -

$1182.84], \mathrm{P}<0.0001)$, and TNM III/IV stage $(\mathrm{OR}=2.94[1.42-6.07], \mathrm{P}=0.003)$ than patients with a

119 normal weight. Subjects in the obese group also had a greater risk of ETE (OR=1.82[1.23-2.71],

$120 \mathrm{P}=0.002)$ and high $\mathrm{T}$ stage $(\mathrm{OR}=1.82[1.23-2.70], \mathrm{P}=0.003)$ than normal weight subjects.

121 Whether in the overweight or obese group, BMI has no correlation with lymph node metastasis.

122 Among female patients, compared to the normal weight group, the overweight group had a

123 greater risk of ETE $(\mathrm{OR}=2.10[1.43-3.08], \mathrm{P}=0.0002)$, high $\mathrm{T}$ stage $(\mathrm{OR}=2.10[1.43-3.08], \mathrm{P}$ 
$124=0.0002)$, and TNM III/IV tumors $(\mathrm{OR}=2.86[1.18-6.94], \mathrm{P}=0.02)$; the obese group had a greater

125 risk of ETE $(\mathrm{OR}=2.45[1.58-3.82], \mathrm{P}<0.000)$, high $\mathrm{T}$ stage $(\mathrm{OR}=2.45[1.58-3.82], \mathrm{P}<0.000)$, and

126 TNM III/IV tumors $(\mathrm{OR}=3.99[1.55-10.28], \mathrm{P}=0.0004)$ (Table 4). In male patients, no

127 significant differences were observed (S1).

128 When the patient's age was $\geq 55$ years, ETE, high T stage, and TNM III/IV tumors were more

129 common in the overweight group than in the normal weight group, with ORs $=2.19(1.22$ -

130 3.89), $\mathrm{P}=0.009$, ORs $=2.18(1.22-3.89), \mathrm{P}=0.008$, and $\mathrm{ORs}=2.42(1.15-5.13), \mathrm{P}=0.02$, respectively.

131 ETE $(\mathrm{OR}=2.03[1.06-3.89], \mathrm{P}=0.03)$ and high $\mathrm{T}$ stage $(\mathrm{OR}=2.03[1.06-3.89], \mathrm{P}=0.03)$ were each

132 more frequent in the obese group than in the normal weight group (Table 5).

133 When the patient's age was $<55$ years, ETE and high T stage tumors were more common in the

134 overweight group than in the normal weight group, with $\mathrm{ORs}=1.77(1.14-2.74), \mathrm{P}=0.01$, ORs

$135=1.80(1.16-2.78), \mathrm{P}=0.008$ respectively. ETE $(\mathrm{OR}=1.70[1.02-2.83], \mathrm{P}=0.04)$, high T stage

$136(\mathrm{OR}=1.68[1.01-2.80], \mathrm{P}=0.04)$ and multifocality $(\mathrm{OR}=1.50[1.08-2.09], \mathrm{P}=0.02)$ were each

137 more frequent in the obese group than in the normal weight group (Table 6).

138 Discussion

139 Thyroid cancer is the most common malignant tumor in the endocrine system. Its incidence has 140 increased year by year in the past 20 years. In 2012, the number of new cases of thyroid cancer

141 in China accounted for $15.6 \%$ of the global number of new cases, and the number of deaths

142 accounted for $13.8 \%^{2}$.PTC is the most common histological type of thyroid cancer, accounting

143 for about $80 \%$ of its incidence[14].In recent decades, advances in thyroid ultrasonography,

144 increased use of fine needle biopsy, and occasional findings from other neck imaging studies

145 have been made; however, these do not fully explain the increasing incidence of PTC, including

146 stage III and IV PTC. Some scholars speculate that this incidence may be affected by other 
147 factors such as the environment and lifestyle ${ }^{3,4}$.At the same time, several epidemiological

148 studies on obesity and cancer have found that the risks of endometrial, colorectal, breast, thyroid, 149 and prostate cancer are closely related to BMI, and the risk of PTC is positively correlated with $150 \mathrm{BMI}[15,16]$. It is concerning that with the urbanization of China, the number of overweight and 151 obese patients has become high, and the Chinese population is no longer a population with a low 152 average BMI. According to statistics, overweight and obese people account for close to $29.2 \%$ of 153 the total population of China [17].In this study, the 17 underweight patients accounted for only $1541 \%$ of the patients enrolled, while those who were overweight and obese accounted for $59.2 \%$. 155 The epidemiology of obesity and PTC is shows significant time-trend correlations, suggesting 156 that obesity acts as a risk factor for the occurrence and development of PTC [5].

157 At present, the relationship between obesity and the pathological features of PTC remains 158 controversial. Kim et al. found that the risk of ETE among patients with PTC increases with the 159 increase in BMI, and is closely related to the multifocality of the tumor [18].Another study 160 showed that elevated BMI is associated with tumor size and TNM staging[19] .Our study used 161 the Chinese BMI standard and the TNM staging of the eighth edition of AJCC for all patients. 162 Based on multiple logistic regression, the results showed that the proportion of TNM III/IV 163 tumors $(\mathrm{OR}=2.86[1.18-6.94], \mathrm{P}=0.02)$ and the risk of $\mathrm{ETE}(\mathrm{OR}=1.99[1.41-2.81], \mathrm{P}<0.0001)$

164 increased significantly in overweight group, while tumor size, lymph node metastasis, and 165 multifocal tumors were not significantly associated with BMI; the risk of ETE $(\mathrm{OR}=1.82[1.23$ 2.71], $\mathrm{P}=0.002$ ) in the obese group increased with BMI. Kim et al. found that BMI is associated with tumor invasion, lymphatic invasion, lymph node metastasis, and tumor multifocality, in patients with PTC [20].In contrast, some studies suggest that there is no significant correlation 169 between obesity, and clinical pathological features and the recurrence of PTC[9, 11] .It is worth 
170 noting that clinical BMI has certain limitations as the sole criterion for assessing obesity,

171 especially when it reflects the lack of specificity in centripetal obesity[21].This may be an

172 important reason for the difference in the conclusions of the above studies. We look forward to

173 establishing a more comprehensive obesity evaluation index system, including BMI and

174 abdominal circumference index, in future research.

175 At present, molecular mechanisms related to obesity and tumors indicate that obesity can

176 promote tumor invasion and metastasis through a variety of obesity-related factors and metabolic

177 pathways $[22,23]$.Adiponectin can reduce the expression of vascular endothelial growth factor

178 (VEGF) and B-cell lymphoma factor-2 (Bcl-2), increase the activity of tumor suppressors such

179 as P53, and inhibit tumor growth and survival. Obesity causes a decrease in adiponectin, and the

180 loss of its receptor expression may be an important mechanism for promoting the progression of

181 PTC. Leptin can increase the expression of VEGF, interleukin-6 (IL-6), and tumor necrosis

182 factor- $\alpha(\mathrm{TNF}-\alpha)$ to promote progression and metastasis of thyroid cancer[24]. Overexpression

183 of leptin and its receptors is significantly associated with the aggressiveness of thyroid

184 cancer[25]. Kim et al. found that a high-fat diet induced more aggressive pathological changes,

185 which were mediated by increased activation of the Janus kinase 2-signaling transducer,

186 activation of the transcription 3 (STAT3) signaling pathway, and induction of STAT3 target gene

187 expression[26]. The discovery of these mechanisms not only reveals the potential molecular

188 basis of obesity as a risk factor in the development and progression of thyroid cancer, but also

189 provides a new therapeutic direction for the future.

190 Conclusions

191 In summary, obesity is closely related to the risk of PTC and the invasiveness of tumors.

192 Controlling body weight through regular exercise and a reasonable diet and reducing obesity 
193 should be important prevention and treatment methods for patients with papillary thyroid cancer

194 and high-risk groups.

\section{Acknowledgements}

196 This work was supported by grants from National Natural Science Foundation of China (Grant

197 Nos. 81872169,81702629), Tianjin key research and development program science and

198 technology support key projects (Grant No. 17YFZCSY00690), and Tianjin Municipal Science

199 and technology project(Grant No. 19JCYBJC27400). There was no additional external funding

200 received for this study.

201

202

203

204

205

206

207

208

209

210

211

212

213

214

215

216

217

218

219

220

221

222

223

224

225

226

227

228

229

230

231

232

233

234

235

236

\section{References:}

[1] Siegel RL, Miller KD and Jemal A. Cancer statistics, 2018. CA Cancer J Clin 2018, 68: 7-30.

[2] McGuire S. World Cancer Report 2014. Geneva, Switzerland: World Health Organization, International Agency for Research on Cancer, WHO Press, 2015. ADV NUTR 2016, 7: 418-419.

[3] Chen AY, Jemal A and Ward EM. Increasing incidence of differentiated thyroid cancer in the United States, 1988-2005. CANCER-AM CANCER SOC 2009, 115: 3801-3807.

[4] Enewold L, Zhu K, Ron E, Marrogi AJ, Stojadinovic A, Peoples GE and Devesa SS. Rising Thyroid Cancer Incidence in the United States by Demographic and Tumor Characteristics, 1980-2005. CANCER EPIDEM BIOMAR 2009, 18: 784-791.

[5] Pappa T and Alevizaki M. Obesity and thyroid cancer: a clinical update. THYROID 2014, 24: $190-199$.

[6] Schmid D, Ricci C, Behrens G and Leitzmann MF. Adiposity and risk of thyroid cancer: a systematic review and meta-analysis. OBES REV 2015, 16: 1042-1054.

[7] Patel D, Kitahara CM, Park Y, Liao LM, Linet M, Kebebew E and Nilubol N. Thyroid Cancer and Nonsteroidal Anti-Inflammatory Drug Use: A Pooled Analysis of Patients Older Than 40 Years of Age. THYROID 2015, 25: 1355-1362.

[8] Yin D, He H, Yu K, Xie J, Lei M, Ma R, Li H, Wang Y and Liu Z. The association between thyroid cancer and insulin resistance, metabolic syndrome and its components: A systematic review and meta-analysis. INT J SURG 2018, 57: 66-75.

[9] Kwon H, Kim M, Choi YM, Jang EK, Jeon MJ, Kim WG, Kim TY, Shong YK, Song DE, Baek JH, Hong SJ and Kim WB. Lack of Associations between Body Mass Index and Clinical Outcomes in Patients with Papillary Thyroid Carcinoma. Endocrinol Metab (Seoul) 2015, 30: 305-311.

[10] Paes JE, Hua K, Nagy R, Kloos RT, Jarjoura D and Ringel MD. The relationship between body mass index and thyroid cancer pathology features and outcomes: a clinicopathological cohort study. J Clin Endocrinol Metab 2010, 95: 4244-4250.

[11] Grani G, Lamartina L, Montesano T, Ronga G, Maggisano V, Falcone R, Ramundo V, Giacomelli L, Durante $\mathrm{C}$, Russo D and Maranghi M. Lack of association between obesity and aggressiveness of differentiated thyroid cancer. J ENDOCRINOL INVEST 2019, 42: 85-90.

[12] Lee J, Lee CR, Ku CR, Kang SW, Jeong JJ, Shin DY, Nam KH, Jung SG, Lee EJ, Chung WY and Jo YS. Association Between Obesity and BRAFV600E Mutation Status in Patients with Papillary Thyroid Cancer. ANN SURG ONCOL 2015, 22 Suppl 3: S683-S690.

[13] Qian J, Li N and Ren X. Obesity and depressive symptoms among Chinese people aged 45 and over. SCI REP-UK 2017, 7.

[14] Ahmad F, Nathani R, Venkat J, Bharda A, Vanere V, Bhatia S and Das BR. Molecular evaluation of BRAF gene mutation in thyroid tumors: Significant association with papillary tumors and extra thyroidal extension indicating its role as a biomarker of aggressive disease. EXP MOL PATHOL 2018, 105: 380-386.

Peer) reviewing PDF | (2020:03:46744:1:2:NEW 10 Jun 2020) 
237 [15] Lauby-Secretan B, Scoccianti C, Loomis D, Grosse Y, Bianchini F and Straif K. Body Fatness and Cancer-238 Viewpoint of the IARC Working Group. N Engl J Med 2016, 375: 794-798.

239 [16] Ma J, Huang M, Wang L, Ye W, Tong Y and Wang H. Obesity and risk of thyroid cancer: evidence from a 240 meta-analysis of 21 observational studies. Med Sci Monit 2015, 21: 283-291.

241 [17] Gordon-Larsen P, Wang H and Popkin BM. Overweight dynamics in Chinese children and adults. OBES

242 REV 2014, 15: 37-48.

243 [18] Kim SK, Woo JW, Park I, Lee JH, Choe JH, Kim JH and Kim JS. Influence of Body Mass Index and Body 244 Surface Area on the Behavior of Papillary Thyroid Carcinoma. THYROID 2016, 26: 657-666.

245 [19] Dieringer P, Klass EM, Caine B and Smith-Gagen J. Associations between body mass and papillary thyroid cancer stage and tumor size: a population-based study. J CANCER RES CLIN 2015, 141: 93-98.

[20] Kim S, Park HS, Kim K, Yoo H, Chae B, Bae J, Jung S and Song B. Correlation between obesity and clinicopathological factors in patients with papillary thyroid cancer. SURG TODAY 2015, 45: 723-729.

[21] Rosen ED and Spiegelman BM. What We Talk About When We Talk About Fat. CELL 2014, 156: 20-44.

[22] Marcello MA, Cunha LL, Batista FA and Ward LS. Obesity and thyroid cancer. Endocr Relat Cancer 2014, 21: T255-T271.

252 [23] Avgerinos KI, Spyrou N, Mantzoros CS and Dalamaga M. Obesity and cancer risk: Emerging biological mechanisms and perspectives. METABOLISM 2019, 92: 121-135.

[24] Vansaun MN. Molecular pathways: adiponectin and leptin signaling in cancer. CLIN CANCER RES 2013, 19: 1926-1932.

[25] Fan YL and Li XQ. Expression of leptin and its receptor in thyroid carcinoma: distinctive prognostic significance in different subtypes. Clin Endocrinol (Oxf) 2015, 83: 261-267.

258 [26] Park S, Willingham MC, Qi J and Cheng SY. Metformin and JQ1 synergistically inhibit obesity-activated thyroid cancer. Endocr Relat Cancer 2018, 25: 865-877.

261 


\section{Table 1 (on next page)}

Clinicopathological characteristics of 1579 patients with papillary thyroid carcinoma 
1 Table1.Clinicopathological characteristics of 1579 patients with papillary thyroid carcinoma

\begin{tabular}{ll}
\hline Clinicopathological characteristics & $\mathrm{n}=1579$ \\
\hline Gender & $1233(78.1 \%)$ \\
$\quad$ Female & $346(21.9 \%)$ \\
$\quad$ Male & $45.98 \pm 10.93$ \\
age & $1129(71.5 \%)$ \\
$\quad<55$ & $450(28.5 \%)$ \\
$\quad \geq 55$ & \\
Tumor size & $906(57.4 \%)$ \\
$<1$ cm & $673(42.6 \%)$ \\
$\geq 1$ cm & $228(14.4 \%)$ \\
Extrathyroidal invasion & $565(35.5 \%)$ \\
multifocality & \\
T staging & $1322(83.7 \%)$ \\
T 1 & $28(1.8 \%)$ \\
T2 & $153(9.7 \%)$ \\
T3 & $76(4.8 \%)$ \\
T 4 & \\
N staging & $875(55.4 \%)$ \\
N0 & $441(27.9 \%)$ \\
N1a & $263(16.7 \%)$ \\
N1b & \\
TNM staging & $1515(95.9 \%)$ \\
I / II & $64(4.1 \%)$ \\
IIIIV & \\
&
\end{tabular}

2 


\section{Table 2 (on next page)}

demographic and clinico-pathological characteristics of patients with different BMI 
1 Table2. demographic and clinico-pathological characteristics of patients with different BMI

\begin{tabular}{|c|c|c|c|c|c|c|}
\hline characteristic & $\begin{array}{c}\mathrm{BMI}<18.5 \\
\mathrm{~N}(\%)\end{array}$ & $\begin{array}{c}18.5 \leq \mathrm{BMI}<24 \\
\mathrm{~N}(\%)\end{array}$ & $\begin{array}{c}24 \leq \mathrm{BMI}<28 \\
\mathrm{~N}(\%)\end{array}$ & $\begin{array}{c}\mathrm{BMI} \geq 28 \\
\mathrm{~N}(\%)\end{array}$ & $\chi^{2}$ & $\mathrm{P}$ \\
\hline \multicolumn{7}{|l|}{ gender } \\
\hline male & $0(0.00)$ & $78(12.44)$ & $141(24.23)$ & $127(35.98)$ & 80.28 & $<0.0001$ \\
\hline female & $17(100.00)$ & $549(87.56)$ & $441(75.77)$ & $226(64.02)$ & & \\
\hline \multicolumn{7}{|l|}{ age } \\
\hline$<55$ & $14(82.35)$ & 494(78.79) & $378(64.95)$ & $242(68.75)$ & 27.05 & $<0.0001$ \\
\hline$\geq 55$ & $3(17.65)$ & $133(21.21)$ & $204(35.05)$ & $110(31.25)$ & & \\
\hline \multicolumn{7}{|l|}{$\mathrm{TSH}$} \\
\hline normal & $16(94.12)$ & $590(94.10)$ & $552(94.85)$ & $327(92.63)$ & 1.92 & 0.5884 \\
\hline abnormal & $1(5.88)$ & $37(5.90)$ & $30(5.15)$ & $26(7.37)$ & & \\
\hline \multicolumn{7}{|c|}{ Number of tumors } \\
\hline 1 & $12(70.59)$ & $415(66.19)$ & $373(64.09)$ & $218(61.76)$ & 2.26 & 0.5207 \\
\hline$\geq 2$ & $5(29.41)$ & $212(33.81)$ & $209(35.91)$ & $135(38.24)$ & & \\
\hline \multicolumn{7}{|l|}{ Tumor size } \\
\hline$<1$ & $8(47.06)$ & $374(59.65)$ & $326(56.01)$ & 198(56.09) & 2.74 & 0.4327 \\
\hline$\geq 1$ & $9(52.94)$ & $253(40.35)$ & $256(43.99)$ & $155(43.91)$ & & \\
\hline \multicolumn{7}{|c|}{ Extrathyroidl extension } \\
\hline absent & $16(94.12)$ & $567(90.43)$ & $475(81.62)$ & $293(83.00)$ & 22.25 & $<0.0001$ \\
\hline present & $1(5.88)$ & $60(9.57)$ & $107(18.38)$ & $60(17.00)$ & & \\
\hline \multicolumn{7}{|c|}{ lymph node metastasis } \\
\hline absent & $8(47.06)$ & $348(55.50)$ & $332(57.04)$ & $187(52.97)$ & 1.96 & 0.5810 \\
\hline present & $9(52.94)$ & $279(44.50)$ & $250(42.96)$ & $166(47.03)$ & & \\
\hline \multicolumn{7}{|l|}{$\mathrm{T}$ staging } \\
\hline $\mathrm{I}+\mathrm{II}$ & $16(94.12)$ & $567(90.43)$ & $474(81.44)$ & 293(83.00) & 22.81 & $<0.0001$ \\
\hline $\mathrm{III}+\mathrm{IV}$ & $1(5.88)$ & $60(9.57)$ & $108(18.56)$ & $60(17.00)$ & & \\
\hline \multicolumn{7}{|l|}{ TNM staging } \\
\hline $\mathrm{I}+\mathrm{II}$ & $17(100.00)$ & $617(98.41)$ & $545(93.64)$ & $336(95.18)$ & - & $0.0002 *$ \\
\hline $\mathrm{III}+\mathrm{IV}$ & $0(0.00)$ & $10(1.59)$ & $37(6.36)$ & $17(4.82)$ & & \\
\hline
\end{tabular}

*fisher exact test was performed because one expected frequency less than 1 


\section{Table 3 (on next page)}

Logistic regression of BMI level on different adverse clinico-pathological characteristics 
Table3. Logistic regression of BMI level on different adverse clinico-pathological characteristics

\begin{tabular}{|c|c|c|c|c|}
\hline & $\begin{array}{c}\mathrm{BMI}<18.5 \\
\mathrm{~N}=17\end{array}$ & $\begin{array}{c}18.5 \leq \mathrm{BMI}<24 \\
\mathrm{~N}=627\end{array}$ & $\begin{array}{c}24 \leq \mathrm{BMI}<28 \\
\mathrm{~N}=582\end{array}$ & $\begin{array}{c}\mathrm{BMI} \geq 28 \\
\mathrm{~N}=353\end{array}$ \\
\hline \multicolumn{5}{|l|}{ Multifocality } \\
\hline OR $(95 \% \mathrm{CI})$ & $0.80(0.28,2.31)$ & Reference & $1.12(0.88,1.43)$ & $1.26(0.95,1.66)$ \\
\hline $\mathrm{P}$ & 0.68 & & 0.36 & 0.10 \\
\hline \multicolumn{5}{|c|}{ tumor size $\geq 1 \mathrm{~cm}$} \\
\hline OR $(95 \% \mathrm{CI})$ & $1.69(0.64,4.46)$ & Reference & $1.13(0.89,1.43)$ & $1.12(0.84,1.45)$ \\
\hline $\mathrm{P}$ & 0.28 & & 0.29 & 0.47 \\
\hline \multicolumn{5}{|c|}{ Extrathyroidl extension } \\
\hline OR $(95 \% \mathrm{CI})$ & $0.60(0.08,4.65)$ & Reference & $1.99(1.41,2.81)$ & $1.82(1.23,2.71)$ \\
\hline $\mathrm{P}$ & 0.63 & & $<0.0001$ & 0.002 \\
\hline \multicolumn{5}{|c|}{ lymph node metastasis } \\
\hline OR $(95 \% \mathrm{CI})$ & $1.47(0.56,3.87)$ & Reference & $0.92(0.73,1.16)$ & $1.02(0.78,1.34)$ \\
\hline $\mathrm{P}$ & 0.43 & & 0.48 & 0.88 \\
\hline \multicolumn{5}{|c|}{ T staging (stage III + IV) } \\
\hline OR $(95 \% \mathrm{CI})$ & $0.61(0.08,4.66)$ & Reference & $2.01(1.43,2.84)$ & $1.82(1.23,2.70)$ \\
\hline $\mathrm{P}$ & 0.63 & & $<0.0001$ & 0.003 \\
\hline \multicolumn{5}{|c|}{ TNM staging (stage III + IV) } \\
\hline OR $(95 \% \mathrm{CI})$ & - & Reference & $2.94(1.42,6.07)$ & $2.23(0.99,5.05)$ \\
\hline $\mathrm{P}$ & - & & 0.003 & 0.05 \\
\hline
\end{tabular}


Table 4 (on next page)

Logistic regression of BMI level on different adverse clinico-pathological characteristics (female) 
1 Table4. Logistic regression of BMI level on different adverse clinico-pathological characteristics (female)

\begin{tabular}{|c|c|c|c|c|}
\hline & $\begin{array}{c}\mathrm{BMI}<18.5 \\
\mathrm{~N}=17\end{array}$ & $\begin{array}{c}18.5 \leq \mathrm{BMI}<24 \\
\mathrm{~N}=549\end{array}$ & $\begin{array}{c}24 \leq \mathrm{BMI}<28 \\
\mathrm{~N}=441\end{array}$ & $\begin{array}{c}\mathrm{BMI} \geq 28 \\
\mathrm{~N}=226\end{array}$ \\
\hline \multicolumn{5}{|l|}{ Multifocality } \\
\hline OR $(95 \% \mathrm{CI})$ & $0.80(0.28,2.30)$ & Reference & $1.07(0.82,1.39)$ & $1.34(0.97,1.85)$ \\
\hline $\mathrm{P}$ & 0.68 & & 0.64 & 0.08 \\
\hline \multicolumn{5}{|c|}{ tumor size $\geq 1 \mathrm{~cm}$} \\
\hline OR $(95 \% \mathrm{CI})$ & $1.68(0.64,4.44)$ & Reference & $1.14(0.89,1.48)$ & $1.07(0.78,1.47)$ \\
\hline $\mathrm{P}$ & 0.29 & & 0.30 & 0.68 \\
\hline \multicolumn{5}{|c|}{ Extrathyroidl extension } \\
\hline OR $(95 \% \mathrm{CI})$ & $0.64(0.08,4.95)$ & Reference & $2.10(1.43,3.08)$ & $2.45(1.58,3.82)$ \\
\hline $\mathrm{P}$ & 0.67 & & 0.0002 & $<0.000$ \\
\hline \multicolumn{5}{|c|}{ lymph node metastasis } \\
\hline OR $(95 \% \mathrm{CI})$ & $1.53(0.58,4.03)$ & Reference & $0.94(0.73,1.22)$ & $1.19(0.88,1.64)$ \\
\hline $\mathrm{P}$ & 0.39 & & 0.66 & 0.27 \\
\hline \multicolumn{5}{|c|}{ T staging (stage III + IV) } \\
\hline OR $(95 \% \mathrm{CI})$ & $0.64(0.08,4.95)$ & Reference & $2.10(1.43,3.08)$ & $2.45(1.58,3.82)$ \\
\hline $\mathrm{P}$ & 0.67 & & 0.0002 & $<0.000$ \\
\hline \multicolumn{5}{|c|}{ TNM staging (stage III + IV) } \\
\hline OR $(95 \% \mathrm{CI})$ & - & Reference & $2.86(1.18,6.94)$ & $3.99(1.55,10.28)$ \\
\hline $\mathrm{P}$ & - & & 0.02 & 0.0004 \\
\hline
\end{tabular}




\section{Table 5 (on next page)}

Logistic regression of BMI level on different adverse clinico-pathological characteristics (age $\geq 55$ ) 
1 Table5. Logistic regression of BMI level on different adverse clinico-pathological characteristics (age $\geq \mathbf{5 5}$ )

\begin{tabular}{|c|c|c|c|c|}
\hline & $\begin{array}{c}\mathrm{BMI}<18.5 \\
\mathrm{~N}=3\end{array}$ & $\begin{array}{c}18.5 \leq \mathrm{BMI}<24 \\
\mathrm{~N}=133\end{array}$ & $\begin{array}{c}24 \leq \mathrm{BMI}<28 \\
\mathrm{~N}=204\end{array}$ & $\begin{array}{l}\mathrm{BMI} \geq 28 \\
\mathrm{~N}=110\end{array}$ \\
\hline \multicolumn{5}{|l|}{ Multifocality } \\
\hline OR $(95 \% \mathrm{CI})$ & - & Reference & $1.02(0.65,1.60)$ & $0.76(0.45,1.31)$ \\
\hline $\mathrm{P}$ & - & & 0.95 & 0.32 \\
\hline \multicolumn{5}{|c|}{ tumor size $\geq 1 \mathrm{~cm}$} \\
\hline OR $(95 \% \mathrm{CI})$ & - & Reference & $1.38(0.88,2.15)$ & $1.28(0.77,2.14)$ \\
\hline $\mathrm{P}$ & - & & 0.16 & 0.34 \\
\hline \multicolumn{5}{|c|}{ Extrathyroidl extension } \\
\hline OR $(95 \% \mathrm{CI})$ & - & Reference & $2.19(1.22,3.89)$ & $2.03(1.06,3.89)$ \\
\hline $\mathrm{P}$ & - & & 0.009 & 0.03 \\
\hline \multicolumn{5}{|c|}{ lymph node metastasis } \\
\hline OR $(95 \% \mathrm{CI})$ & - & Reference & $1.07(0.68,1.67)$ & $1.18(0.71,1.98)$ \\
\hline $\mathrm{P}$ & - & & 0.78 & 0.52 \\
\hline \multicolumn{5}{|c|}{ T staging (stage III + IV) } \\
\hline OR $(95 \% \mathrm{CI})$ & - & Reference & 2.18(1.22,3.89) & $2.03(1.06,3.89)$ \\
\hline $\mathrm{P}$ & - & & 0.008 & 0.03 \\
\hline \multicolumn{5}{|c|}{ TNM staging (stage III + IV) } \\
\hline OR $(95 \% \mathrm{CI})$ & - & Reference & $2.42(1.15,5.13)$ & $2.01(0.87,4.67)$ \\
\hline $\mathrm{P}$ & - & & 0.02 & 0.10 \\
\hline
\end{tabular}

2 - The number of people in this group is too small to calculate the correlation

3

4 
Table 6(on next page)

Logistic regression of BMI level on different adverse clinico-pathological characteristics (age $<55$ ) 
1 Table6. Logistic regression of BMI level on different adverse clinico-pathological characteristics (age $<\mathbf{5 5})$

\begin{tabular}{|c|c|c|c|c|}
\hline & $\begin{array}{c}\mathrm{BMI}<18.5 \\
\mathrm{~N}=14\end{array}$ & $\begin{array}{c}18.5 \leq \mathrm{BMI}<24 \\
\mathrm{~N}=494\end{array}$ & $\begin{array}{c}24 \leq \mathrm{BMI}<28 \\
\mathrm{~N}=378\end{array}$ & $\begin{array}{l}\mathrm{BMI} \geq 28 \\
\mathrm{~N}=243\end{array}$ \\
\hline \multicolumn{5}{|l|}{ Multifocality } \\
\hline OR $(95 \% \mathrm{CI})$ & $1.13(0.37,3.44)$ & Reference & $1.02(0.65,1.60)$ & $0.76(0.45,1.31)$ \\
\hline $\mathrm{P}$ & 0.82 & & 0.95 & 0.32 \\
\hline \multicolumn{5}{|c|}{ tumor size $\geq 1 \mathrm{~cm}$} \\
\hline OR $(95 \% \mathrm{CI})$ & $2.68(0.88,8.16)$ & Reference & $1.38(0.88,2.15)$ & $1.28(0.77,2.14)$ \\
\hline $\mathrm{P}$ & 0.08 & & 0.16 & 0.34 \\
\hline \multicolumn{5}{|c|}{ Extrathyroidl extension } \\
\hline OR $(95 \% \mathrm{CI})$ & $0.83(0.11,6.49)$ & Reference & $2.19(1.22,3.89)$ & $2.03(1.06,3.89)$ \\
\hline $\mathrm{P}$ & 0.86 & & 0.009 & 0.03 \\
\hline \multicolumn{5}{|c|}{ lymph node metastasis } \\
\hline OR $(95 \% \mathrm{CI})$ & $1.69(0.58,4.95)$ & Reference & $1.07(0.68,1.67)$ & $1.18(0.71,1.98)$ \\
\hline $\mathrm{P}$ & 0.34 & & 0.78 & 0.52 \\
\hline \multicolumn{5}{|c|}{ T staging (stage III + IV) } \\
\hline OR $(95 \% \mathrm{CI})$ & $0.83(0.11,6.52)$ & Reference & $2.18(1.22,3.89)$ & $2.03(1.06,3.89)$ \\
\hline $\mathrm{P}$ & 0.86 & & 0.008 & 0.03 \\
\hline
\end{tabular}

2

3 